\title{
Primary amine-aminopyrimidinebifunctional chiral organocatalysts for the enantioselective conjugate addition of branched aldehydes to maleimides
}

\author{
Pascuala Vízcaíno-Milla ${ }^{a}$ \\ José M. Sansano ${ }^{\mathrm{a}}$ \\ Carmen Nájera ${ }^{*^{a}}$ \\ BélaFiser $^{\text {b }}$ \\ Enrique Gómez-Bengoa ${ }^{\text {*b }}$ \\ ${ }^{a}$ Departamento de Química Orgánica and Centro de Innovación \\ en Química Avanzada (ORFEO-CINQA). Universidad de Alicante, \\ Apdo. 99, E-03080-Alicante, Spain \\ cnajera@ua.es

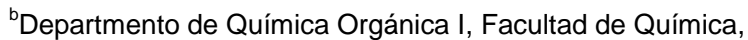 \\ Universidad del País Vasco, Apdo. 1072, E-20080 San Sebastián, \\ Spain \\ enrique.gomez@ehu.es
}

Abstract:Chiral primary amines 6 containing the $(R, R)$ and $(S, S)$-trans-cyclohexane-1,2-diamine scaffold and a 2pyrimidinyl unit are synthesized and used as general organocatalysts for the Michael reaction of $\square$ branched aldehydes to maleimides. The reaction takes place with 10 mol\% organocatalyst loading and hexanedioic acid as cocatalyst in aqueous $\mathrm{N}, \mathrm{N}$-dimethylformamide at $10^{\circ} \mathrm{C}$ affording the corresponding succinimides in good yields and enantioselectivities. DFT calculations support the stereochemical results for the intermolecular process and the bifunctional role played by the organocatalysts.

Key words:Asymmetric Organocatalysis / Maleimides /Succinimides / Aldehydes / Michael addition

Enamine $^{1}$ and iminium ${ }^{2}$ activation mode of carbonyl compounds has promoted the development of asymmetric organocatalysis in the last 15 years. Initially chiral secondary amines have been mainly used in amino-catalysis and more recently primary appears in the stage based on the chemistry of type I aldolases with lysine residues. $^{3} \quad$ Chiral primary amines derived organocatalysts are crucial for enamine formation of hindered carbonyl compounds, namely $\alpha, \alpha$ disubstituted aldehydes. ${ }^{4}$ Several problems have to be overcome with $\alpha$-branched aldehydes apart from steric hindrance, ${ }^{5}$ the formation of low reactive enamines, ${ }^{6}$ and $Z / E$ mixture of diastereomericenamines.

Several enantioselective reactions have been performed such as conjugate additions, aldol and Mannich reactions, and $\alpha$-heterofunctionalization of aldehydes allowing the formation of quaternary stereocenters.

Apart of amino acids derivatives, several bifunctional primary amine organocatalysts derived from chiral 1,2-diamines have been developed. Among them, trans-cyclohexane-1,2diamine, available in both enantiomeric forms, is an excellent rigid chiral scaffold to anchor a moiety able to activate the electrophile by hydrogen bonding lowering the LUMO. ${ }^{7}$ Since pioneers studies from Jacobsen, ${ }^{8}$ Schreiner, ${ }^{9}$ and Takemoto ${ }^{10}$ primary amines-thiourea derivatives have become the most popular organocatalysts. $4 \mathrm{~b}, \mathrm{c}$

Organocatalyzed conjugate addition of $\alpha, \alpha$ disubstituted aldehydes to maleimides is one of the most studied reactions using primary amine catalysts. This process allows easy access to enantiomerically substituted succinimides which are interesting core structural units in natural products and biologically active compounds such as andrimid, moiramide $B$ and hirsutellones $A-E$ with antibacterial activity, haterumaimides A-Q withantitumor activity, and tandospirone which is an anxiolytic and antidepressant drug. ${ }^{11}$ In addition, enantioenriched succinimides can be used as chiral building blocks being easily transformed into pyrrolidines, $\gamma$-lactams, and $\gamma$ lactones. $^{12}$

Bifunctional primary amine-derived organocatalysts from trans-cyclohexane-1,2diamine $(R, R)$-1and its enantiomer bearing a thiourea unit $2,{ }^{13} 3,{ }^{14}$ the guanidine derivative $4,{ }^{15}$ the starting diamine $1,{ }^{16}$ and its $N$-Boc monoprotected derivative $\mathbf{5}^{17}$ promoted efficiently the Michael-type addition of $\alpha, \alpha$-disubstituted aldehydes to maleimides (Figure 1). Recently, we have demonstrated that the 2aminobenzimidazole $\mathrm{e}^{18}$ and 2 aminopyrimidine ${ }^{19}$ units are excellent hydrogen bond donors, the corresponding bifunctional organocatalysts $6^{18}$ and $7^{19}$ being used in Michael and aldol reactions, respectively (Figure 1 ). 
Continuing on this research line and based on the experience of our group in organocatalyzed asymmetric reactions,we envisaged that a primary amine-2aminopyrimidine organocatalyst8 derived from trans-cyclohexane-1,2-diamine could be able to catalyze the conjugate addition of $\alpha, \alpha-$ disubstituted aldehydes to maleimides. DFT calculations would be presented in order toclarifiedthe role of the 2-aminopyrimidine unit as rigid guanidine-type function able to form hydrogen bonds with the carbonyl group of the maleimide acceptor.

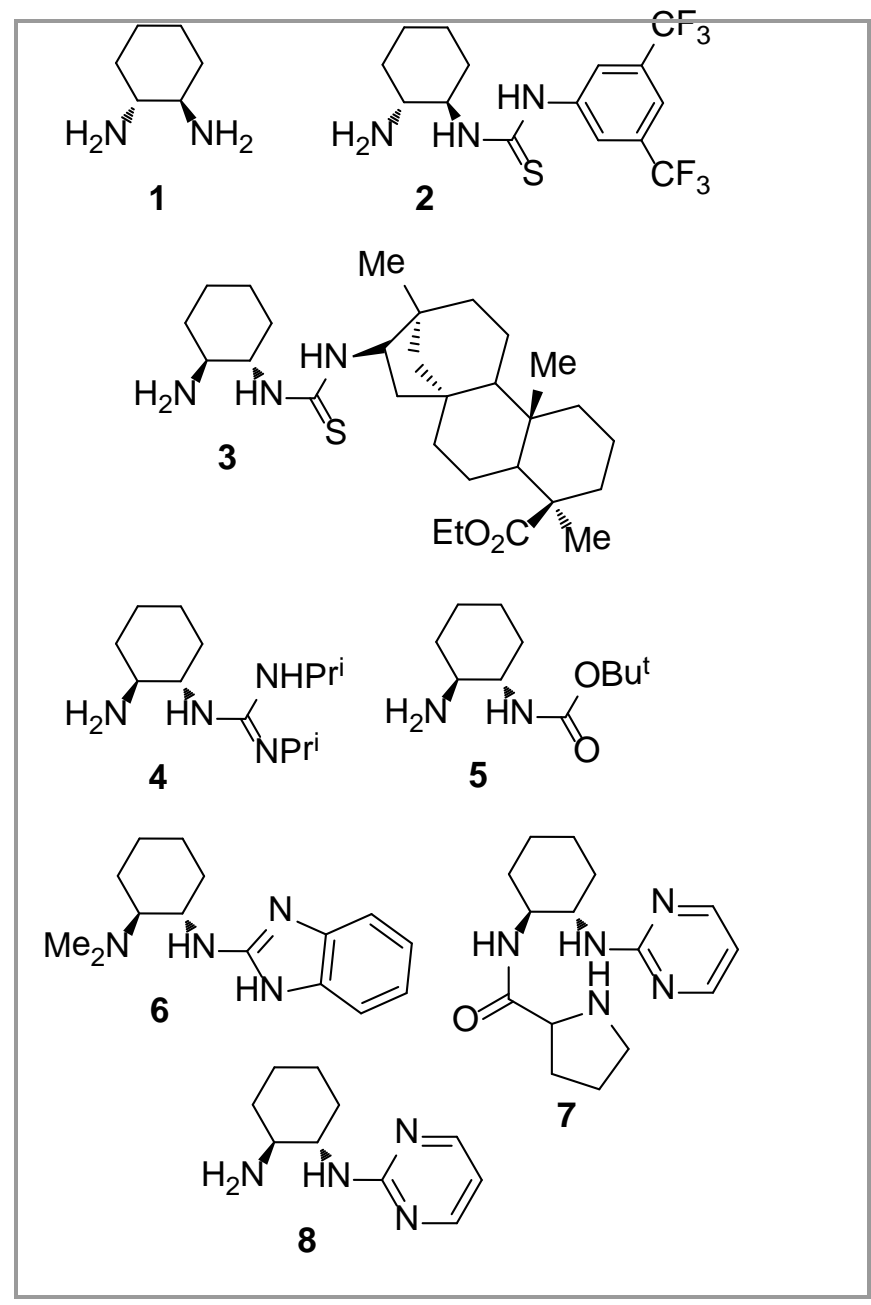

Figure 1 trans-Cyclohexane-1,2-diamine derived organocatalysts

For the synthesis of the primary amineaminopyrimidineorganocatalyst $\mathbf{8}, \quad N$ Bocmonoprotected derivative ent-5 was allowed to react with commercially available 2chloropyrimidine in the presence of triethylamine under isopropanol reflux for $36 \mathrm{~h}$ followed by trifluoroacetic acid deprotection at room temperature in dichloromethane (Scheme
1). ${ }^{19}$ Compound 8 and its enantiomer were obtained in $71 \%$ overall yield.

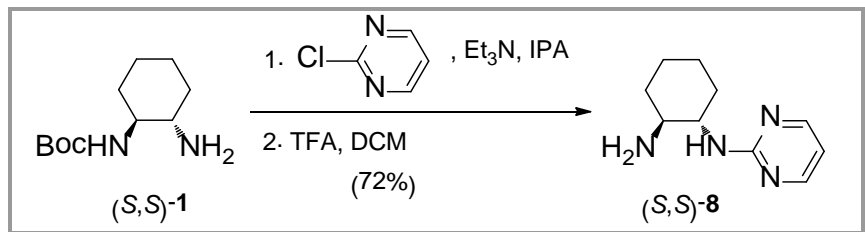

Scheme 1 Synthesis of the organocatalyst $(S, S)-8$

As model reaction isobutyraldehyde (2 equiv) was allowed to react with $N$-phenylmaleimide (NPM) in the presence of $10 \mathrm{~mol} \%$ of the organocatalyst8 (Table 1 ). When the reaction was performed in toluene as solvent at rt for $3 \mathrm{~d}$ the corresponding succinimide $\mathbf{9 a}$ was isolated in $78 \%$ yield as racemic compound (Table 1, entry 1). Under the same reaction conditions using THF instead of toluene the reaction failed and in dichloromethane compound $\mathbf{9 a}$ was isolated in $79 \%$ yield in a modest $29 \%$ ee and with $S$ configuration (Table 1, entries 1 and 2).However, when water was used as solvent 9a was isolated after $3 \mathrm{~d}$ in $74 \%$ yield and $44 \%$ ee with $R$ configuration (Table 1 , entry 4 ). The same sense of enantiomeric bias was observed in DMF with longer reaction times (ca. 6 d), lower yield 33\% in a higher $62 \%$ ee (Table 1, entry 5). Therefore, mixtures $2: 1$ and $4: 1$ of DMF and $\mathrm{H}_{2} \mathrm{O}$ were assayed affording similar results, $70 \%$ yield and $79 \%$ ee (Table 1, entries 6 and 7). The reaction failed in the presence of bases as additives such as DABCO or imidazole (Table 1, entries 8 and 9), which were beneficial in the case of using organocatalysts $\mathbf{1}^{[16]}$ and $\mathbf{4 .}^{[15]}$ On the other hand, when carboxylic acids such as trifluoroacetic, benzoic or hexanedioic (HAD) acids were used as additives the reaction was accelerated only with the two last acids (Table 1, entries 10-12). So with $10 \mathrm{~mol} \%$ of HDA as cocatalyst product $(R)-9$ a was obtained in $80 \%$ yield and $79 \%$ ee. Higher 20 mol\% loading of catalyst and cocatalyst gave the same results (Table 1 , entry 13$)$. By using $(R, R)-\mathbf{8}$, the corresponding ent-9a was obtained (Table 1, entry 14). Finally, lowing the temperature to $0^{\circ} \mathrm{C}$ $2 \mathrm{~d}$ were necessary to the reaction completion giving the product in $83 \%$ isolated yield and in $83 \%$ ee (Table 1, entry 15). Under the last reaction conditions, this conjugate addition of isobutyraldehyde was scale up from $0.3 \mathrm{mmol}$ to ca. $3.5 \mathrm{mmol}$ (0.5 g of NPM) affording (R)-9a after $16 \mathrm{~h}$ reaction time in $99 \%$ crude yield and $85 \%$ ee. Further recrystallization from hexane-ethyl acetate gave pure succinimide in $75 \%$ yield. 


\begin{tabular}{|c|c|c|c|c|c|c|}
\hline & $\mathrm{HO}+\underbrace{\mathrm{N}-1}_{\mathrm{O}}$ & $\begin{array}{r}8(10 n \\
\text { additive }(1 \\
\text { solvent, }\end{array}$ & $\frac{\mathrm{Ol} \%)}{\mathrm{mol} \%)}$ & & & \\
\hline Entry & Solvent & Additive & $\begin{array}{l}\mathrm{T} \\
\left({ }^{\circ} \mathrm{C}\right)\end{array}$ & $\begin{array}{l}\mathrm{t} \\
\text { (h) }\end{array}$ & $\begin{array}{l}\text { Yield } \\
(\%)^{b}\end{array}$ & $\begin{array}{l}e e \\
(\%)^{c}\end{array}$ \\
\hline 1 & $\mathrm{PhMe}$ & - & 25 & 72 & 78 & rac. \\
\hline 2 & THF & - & 25 & 96 & - & - \\
\hline 3 & $\mathrm{CH}_{2} \mathrm{Cl}_{2}$ & - & 25 & 72 & 79 & $24(S)$ \\
\hline 4 & $\mathrm{H}_{2} \mathrm{O}$ & - & 25 & 72 & 74 & $44(R)$ \\
\hline 5 & DMF & - & 25 & 140 & 33 & $62(R)$ \\
\hline 6 & DMF: $\mathrm{H}_{2} \mathrm{O}(2: 1)$ & - & 25 & 72 & 70 & $79(R)$ \\
\hline 7 & DMF: $\mathrm{H}_{2} \mathrm{O}(4: 1)$ & - & 25 & 72 & 71 & $79(R)$ \\
\hline 8 & DMF: $\mathrm{H}_{2} \mathrm{O}(2: 1)$ & DABCO & 25 & 72 & - & - \\
\hline 9 & DMF: $\mathrm{H}_{2} \mathrm{O}(2: 1)$ & Imidazole & 25 & 72 & - & - \\
\hline 10 & DMF: $\mathrm{H}_{2} \mathrm{O}(2: 1)$ & TFA & 25 & 72 & - & - \\
\hline 11 & DMF: $\mathrm{H}_{2} \mathrm{O}(2: 1)$ & $\mathrm{PhCO}_{2} \mathrm{H}$ & 25 & 16 & 84 & $75(R)$ \\
\hline 12 & DMF: $\mathrm{H}_{2} \mathrm{O}(2: 1)$ & $\operatorname{HDA}^{\mathrm{d}}$ & 25 & 16 & 80 & $79(R)$ \\
\hline 13 & DMF: $\mathrm{H}_{2} \mathrm{O}(2: 1)^{\mathrm{e}}$ & $\mathrm{HDA}^{\mathrm{e}}$ & 25 & 15 & 80 & $79(R)$ \\
\hline $14^{\dagger}$ & DMF: $\mathrm{H}_{2} \mathrm{O}(2: 1)$ & HDA & 25 & 18 & 77 & $79(S)$ \\
\hline 15 & DMF: $\mathrm{H}_{2} \mathrm{O}(2: 1)$ & HDA & 0 & 48 & 83 & $86(R)$ \\
\hline
\end{tabular}

${ }^{a}$ Reaction conditions: isobutyraldehyde $(0.6 \mathrm{mmol}), \mathrm{NPM}$ $(0.3 \mathrm{mmol})$, catalyst $8(10 \mathrm{~mol} \%)$ and additive $(10 \mathrm{~mol} \%)$ in $1.0 \mathrm{~mL}$ of solvent.

${ }^{\mathrm{b}}$ Isolated yield after flash chromatography.

${ }^{\mathrm{c}}$ Determined by chiral HPLC.

${ }^{\mathrm{d}}$ Hexanedioic acid.

e $20 \mathrm{~mol} \%$

${ }^{\mathrm{f}}$ The reaction was carried out using ent-8.

Once the optimal reaction conditions were established, that means the use of $10 \mathrm{~mol} \%$ of both, catalyst 8 and HAD as co-catalyst, in 2:1 DMF: $\mathrm{H}_{2} \mathrm{O}$ as solvents at 0 to $5^{\circ} \mathrm{C}$, the scope of the reaction was studied (Scheme 2). The addition of isobutyraldehyde to maleimide and $N$-alkyl maleimides such as $N$-methyl and $N$-benzyl, afforded succinimides $\mathbf{9 b}, \mathbf{c}$ and $\mathbf{d}$ in good yields and 78,80 and $81 \%$ ee, respectively. In the case of the conjugate addition of isobutyraldehyde to $\mathrm{N}$-aryl substituted maleimides the corresponding products $9 \mathrm{e}-\mathrm{g}$ were obtained in higher yields (70$92 \%)$ and ee (86-89\%) (Scheme 2). In order to extend this methodology to other aldehydes cyclopentane- and cyclohexane-carbaldehyde were allowed to react with NPM. The resulting succinimides $9 \mathbf{h}$ and $\mathbf{9 i}$ were isolated in 84 and $89 \%$ yield and in 89 and $93 \%$ ee, respectively (Scheme 2). Low diastereoselectivity was observed in the Michael addition of $\alpha$ phenylpropanal and propanal giving products 9 j and 9 kin 72 and $49 \%$ yield, respectively, and as a mixture $6 / 1$ and $2 / 1$ of diastereomers, respectively. The major isomers $\mathbf{9 j}$ and $\mathbf{9 k}$ were obtained in $81 \%$ and $72 \%$ ee, respectively.

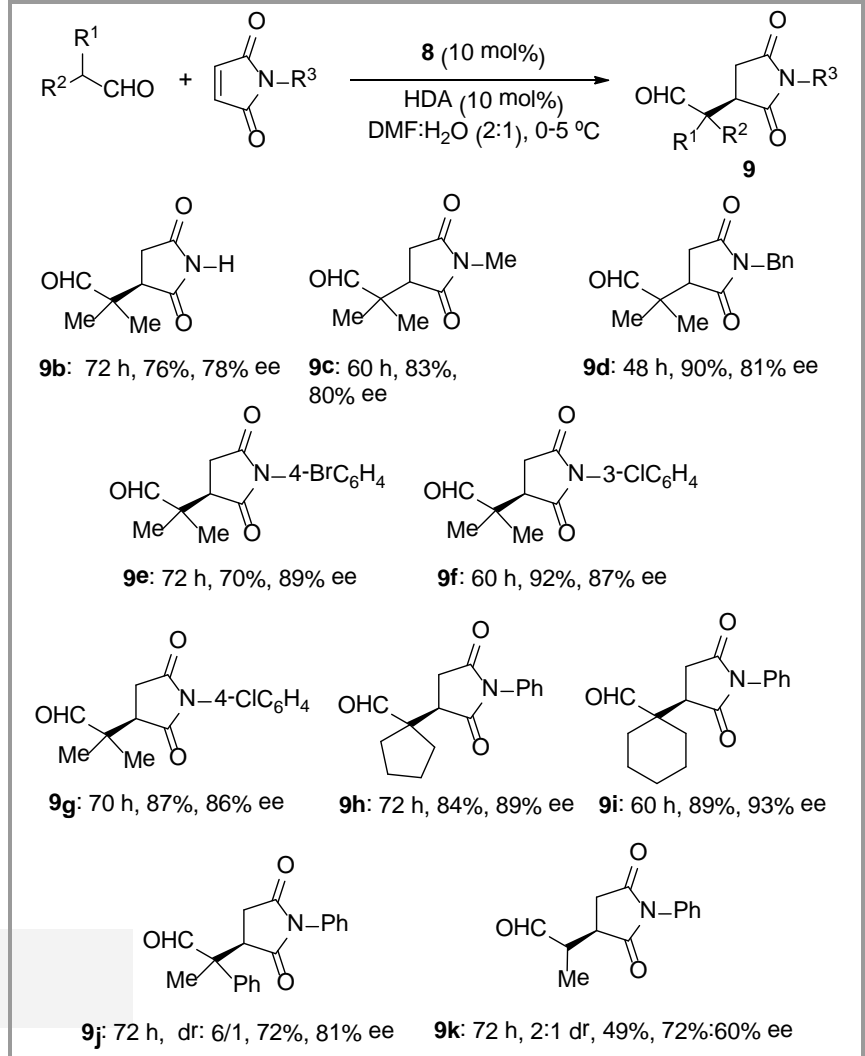

Scheme 2 Synthesis of enantioenriched succinimides 9

The absolute configuration was assigned according to our previous work. ${ }^{15}$ The observed enantioinduction indicates that the catalytic process should takes place through a different activation mode of the 2-aminopyrimidine than the thiourea unit in Takemoto's catalyst. $^{20}$ Experimental work using catalyst 8 with different enantiomeric excess revealed the absence of a nonlinear effect, it means that in the rate determing step only one molecule of the catalyst is involved. From computational studies

\section{Computational studies were carried out}

As conclusion, thetrans-cyclohexane-1,2diaminederived primary amine-2-aminopyrimidine organocatalysts are able to promote the conjugate addition of aldehydes to maleimides with $10 \mathrm{~mol} \%$ loading and using hexanedioic acid as cocatalyst in good yield and up to $93 \%$ ee. The best solvent is DMF and the presence of water as cosolvent has a benefitial effect in the in good yield and up to $93 \%$ ee. reaction time and enantioselectivity. In addition, DFT calculations 
All reagents were purchased from commercial sources and used without further purification. Substrates which were not commercially available were synthesized according to known literature procedures. Catalysts 8 were synthesized as previously described. ${ }^{[19]}$ Melting points were determined with a Reichert Thermovar hot plate apparatus and are uncorrected. IR's were recorded on a JASCO FT-IR 4100 LE (Pike Miracle ATR) and only the structurally most relevant peaks are listed. NMR spectra were performed on a Bruker AC-300 or Bruker Avance-400using $\mathrm{CDCl}_{3}$ as solvent and TMS as internal standard unless otherwise stated. Low-resolution electron impact (El) mass spectra were obtained at $70 \mathrm{eV}$ on Agilent GC/MS-5973N apparatus equipped with a HP$5 \mathrm{MS}$ column (Agilent technologies, $30 \mathrm{~m} \times 0.25 \mathrm{~mm}$ ) and high resolution mass spectra (HRMS-ESI) were obtained on a Waters LCT Premier XE apparatus equipped with a time of flight (TOF) analyzer and the samples were ionized by ESI techniques and introduced through an ultra-high pressure liquid chromatography (UPLC) model Waters ACQUITY H CLASS. Optical rotations were measured on a Jasco P-1030 Polarimeterwith a $5 \mathrm{~cm}$ cell (c given in $g / 100 \mathrm{~mL}$ ). Enantioselectivities were determined by HPLC analysis (Agilent 1100 SeriesHPLC) equipped with a G1315Bdiode array detector and a Quat Pump G1311A equipped with the corresponding Daicel chiral column and the retention time of the major enantiomer is highlighted in bold. Analytical TLC was performed on Merck silica gel plates and the spots visualized with UV light at $254 \mathrm{~nm}$. Flash chromatography employed prepackaged columns ( $12 \mathrm{~mm} \varnothing \times 7.5$ or 15 $\mathrm{cm})$ using Merck silica gel $60(0.040-0.063 \mathrm{~mm})$ and a chromatography pump Büchi Controller C-610-Module C601. Silica gel $60 \mathrm{~F}_{254}$ containing gypsum was employed for preparative layer chromatography.

\section{Conjugate Addition of Aldehydes to Maleimides; General Procedure}

To a solution of 8 or ent $\mathbf{8}(0.03 \mathrm{mmol})$, the maleimide $(0.3$ $\mathrm{mmol})$ and $\mathrm{HDA}(10 \% \mathrm{~mol}, 0.03 \mathrm{mmol})$ in $\mathrm{DMF} / \mathrm{H}_{2} \mathrm{O}(2 / 1$, $\mathrm{v} / \mathrm{v})(0.6 \mathrm{~mL})$ was added the aldehyde $(0.6 \mathrm{mmol})$ and the mixture was stirred at $0^{\circ} \mathrm{C}$ until completion of the reaction (TLC). Then, aqueous $2 \mathrm{M} \mathrm{HCl}(10 \mathrm{~mL})$ was added and the mixture was extracted with AcOEt $(3 \times 10 \mathrm{~mL})$. The organic phase was washed with water $(2 \times 10 \mathrm{~mL})$, dried $\left(\mathrm{MgSO}_{4}\right)$, filtered and evaporated (15 torr). The resulting crude was purified by flash chromatography ( $n$ hexane/AcOEt) affording adducts $\mathbf{9}$.

\section{Supporting Information}

Supporting information for this article is available online at http://www.thiemeconnect.com/products/ejournals/journal/10.1055/s00000084.

\section{Acknowledgment}

The Spanish Ministerio de Ciencia e Innovación (MICINN) (projects CTQ2010-20387, and Consolider Ingenio 2010, CSD2007-00006), the Spanish Ministerio de Economia y Competitividad (MINECO) (projects CTQ2013-43446-P and CTQ2014-51912-REDC), FEDER, the GeneralitatValenciana (PROMETEO 2009/039 and PROMETEOII/2014/017), the Basque Government (GV Grant IT-291-07), the FP7 Marie Curie Actions of the European Commission via the ITN ECHONET network (MCITN-2012-316379) and the Universities of Alicante and Basque Country are gratefully acknowledged for financial support. We also thank SGIker (UPV-EHU) for allocation of computational resources.

\section{References}

(1) List, B.; Lerner, R. A.;Barbas, C. F., III J. Am. Chem. Soc.2002, 122, 2395.

(2) Ahrendt, K. A.; Borthes, C. J.; MacMillan, D. W. C. J. Am. Chem. Soc.2000, 122, 4243.

(3) (a) Wagner, J.; Lerner, R. A.; Barbas, C. F., III Science1995, 270, 1797. (b) Barbas, C. F., III; Heine, A.; Zhong, G.; Hoffmann, T.; Gramatikowa, S.; Bjornestedt, R.; List, B.; Anderson, J.; Stura, E. A.; Wilson, E. A.; Lerner, R. A. Science1997, 278, 2085. (c) Zhong, G. Hoffmann, T.; Lerner, R. A.; Danishefsky, F.; Barbas, C. F., III J. Am. Chem. Soc.1997, 119, 8131. (d) Barbas, C. F., III Barbas, C. F., III Angew. Chem. Int. Ed. 2008, 47, 42.

(4) For recent reviews, see: (a) Desmarchelier, A.; Coeffard, V.; Moreau, X.; Greck, C. Tetrahedron2014, 70, 2491. (b) Tsakos. M.; Kokotos, C. G. Tetrahedron2013, 69,10199. (c)Serdyuk, O. V.; Heckel, C. M.; Tsogoeva, S. B. Org. Biomol. Chem. 2013, 11, 7051.

(5) Sánchez, D.; Bastida, D.; Burés, J.; Isart, C.; Pineda, O.; Vilarrasa, J. Org. Lett.2012, 14, 536.

(6) Kempf, B.; Hampel, N.; Ofial, A. R.; Mayr, H. Chem. Eur. J. 2003, 9, 2209.

(7) (a) Taylor, M. S.; Jacobsen, E. N. Angew. Chem. Int. Ed. 2006, 45, 1520. (b) Yu, X.; Wang, W. Chem. Asian J. 2008, 3, 516. (c)Science of Synthesis, Asymmetric Organocatalysis 1, Lewis Base and Acid Catalysts, List, B., Ed.; Thieme: Stuttgart, 2012.

(8) Sigman, M. S.; Jacobsen, E. N. J. Am. Chem. Soc. 1998, 120, 4901.

(9) Schreiner, P. R.; Wittkopp, A. Org. Lett. 2002, 4, 217.

(10) Okino, T.; Hoashi, Y.; Takemoto, Y. J. Am. Chem. Soc. 2003, 125, 12672.

(11) Chauhan, P. Kaur, J.; Chimni, S. S. Chem. Asian J. 2013, 8, 328.

(12) Kokotos, C. G. Org. Lett. 2013, 15, 2406.

(13) (a) Yu, F.; Yin, Z.; Huang, H.; Ye, T.; Liang, X.; Xe, J. Org. Biomol. Chem. 0, 8, 4767. (b) Bai, J.-F.; Peng, L.; Wang, L.-L.; Wang, L.-X., Xu, X.-Y. Tetrahedron2010, 66, 8928.

(14) Ma, Z.-W.; Liu, Y.-X.; Li, P. L.; Ren, H.; Zhu, Y.; Tao, J.-C. Tetrahedron: Asymmetry 2011, 22, 1740.

(15) (a) Ávila, A.; Chinchilla, R.; Nájera, C. Tetrahedron: Asymmetry 2012, 23, 1625. (b) Ávila, A.; Chinchilla, R.; Gómez-Bengoa, E.; Nájera, C. Eur. J. Org. Chem. 2013, 5085.

(16) Ávila, A.; Chinchilla, R.; Gómez-Bengoa, E.; Nájera, C.

Tetrahedron: Asymmetry 2013, 24, 1531. 
(17) Flores-Ferrándiz, J.; Chinchilla, R. Tetrahedron: Asymmetry 2014, 25, 1091.

(18) (a) Almaşi, D.; Alonso, D. A.; Gómez-Bengoa, E.; Nájera, C. J. Org. Chem.2009, 74, 6163.(b) Gómez-Torres, E.; Alonso, D. A.; Gómez-Bengoa, E.; Nájera, C. Org. Lett.2011, 13, 6106.(c) GómezTorres, E.; Alonso, D. A.; Gómez-Bengoa, E.;
Nájera, C.Eur. J. Org. Chem.2013, 1434. (d) Trillo, P.; Baeza, A.; Nájera, C. Synthesis2014, 46, 3399.

(19) Vizcaíno-Milla, P. ; Sansano, J. M.; Nájera, C.; Fiser, B.; Gómez-Bengoa, E., Eur. J. Org. Chem. 2015, in press.

(20) Bai, J.-F.; Peng, L.; Wang, L.-I.; Wang, L.-X.; Xu, $\begin{array}{ll}\text { X.-Y., } & \text { Tetrahedron 2010, 66,8928. }\end{array}$ 
Organocatalyzed Michael Addition<smiles></smiles>

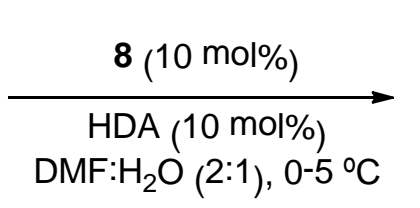<smiles>[R]N1C(=O)CC(C([R])([R])C)C1=O</smiles>

high yields up to $93 \%$ ee<smiles>NC1CCCCC1Nc1ncccn1</smiles>
$(S, S)^{-8}$ 